\title{
Notes on the vocalizations of Black-winged Monarch (Monarcha frater)
}

\section{Peter Boesman}

In the following we briefly analyze and compare voice of the four races of Black-winged Monarch (Monarcha frater). We also try to quantify the extent of any vocal differences using the criteria proposed by Tobias et al. (2010), as a support for taxonomic review.

We have made use of sound recordings available on-line from Xeno Canto (XC) and Macaulay Library (ML).

Song in both Australia and New Guinea consists usually of short melodious whistles sharply going up and down in pitch:

canescens (Australia)
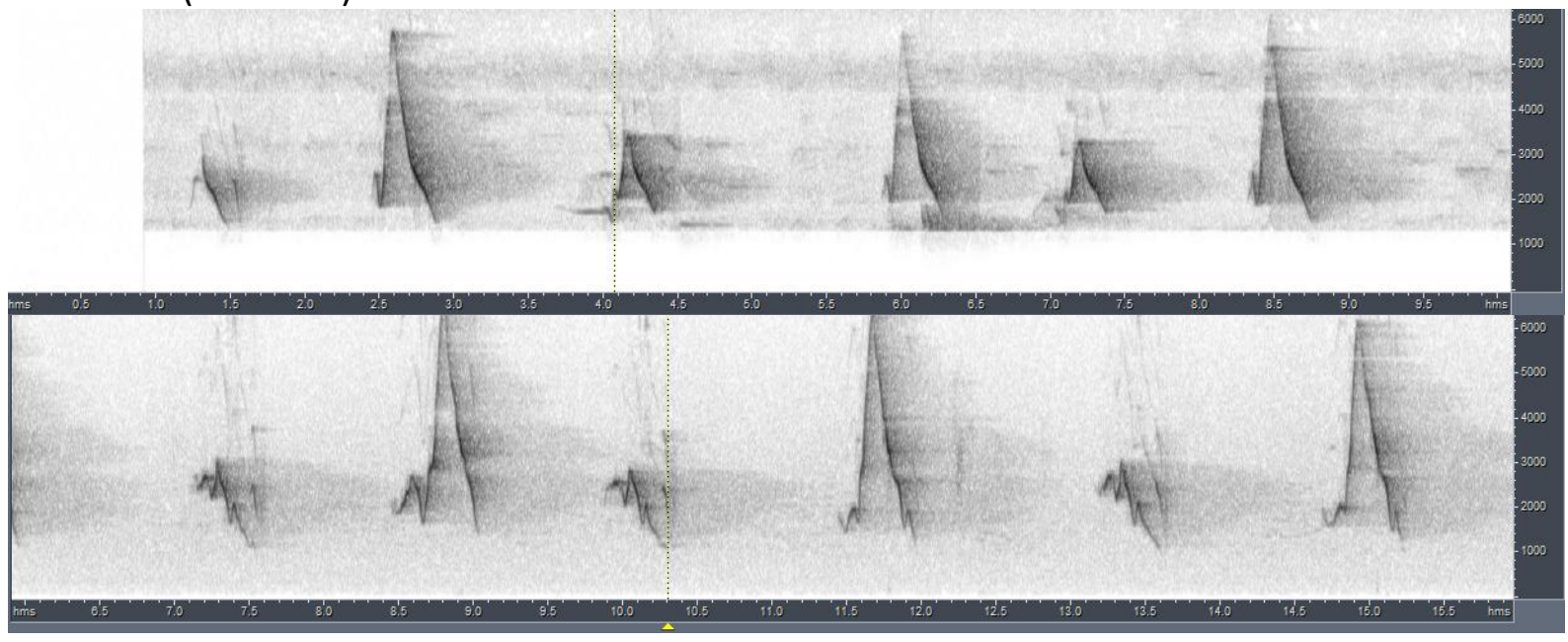

periophthalmicus

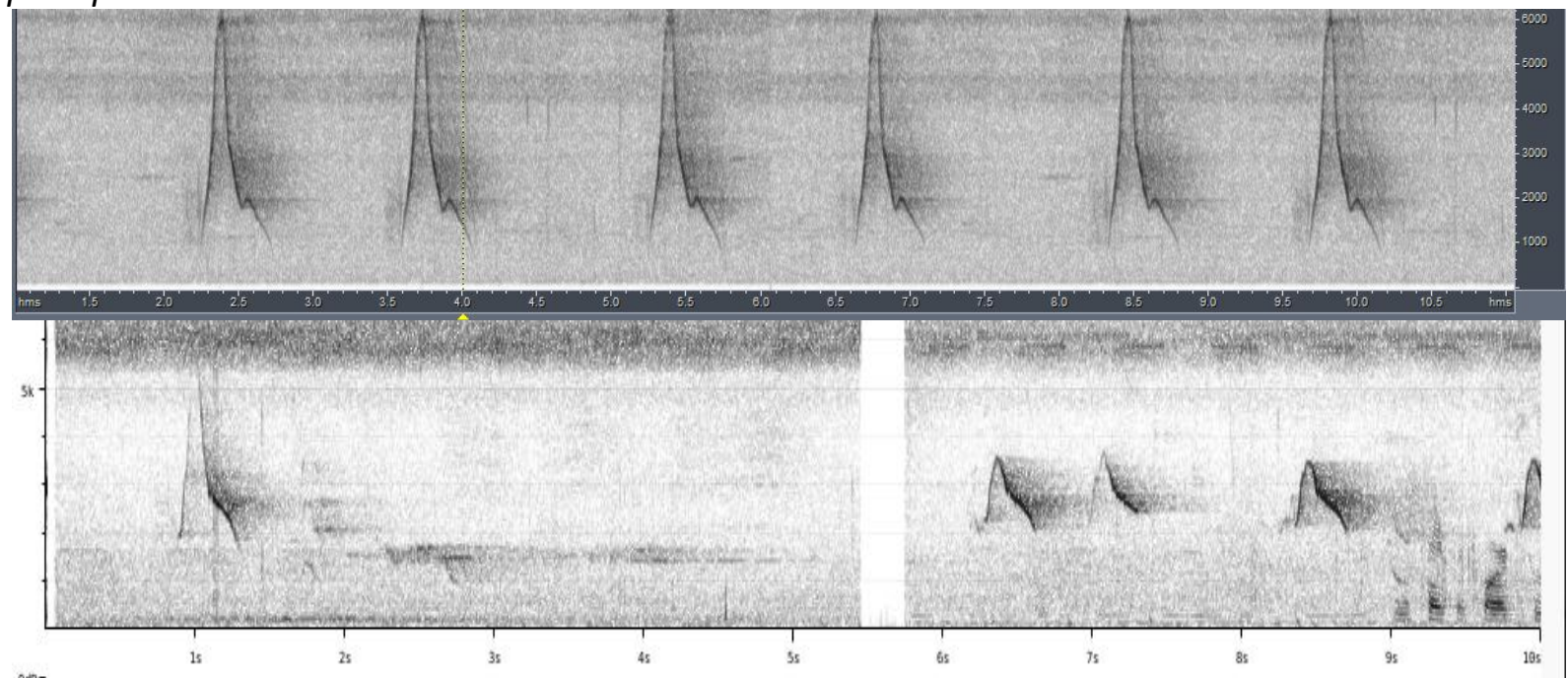

also a single whistle at long intervals: 

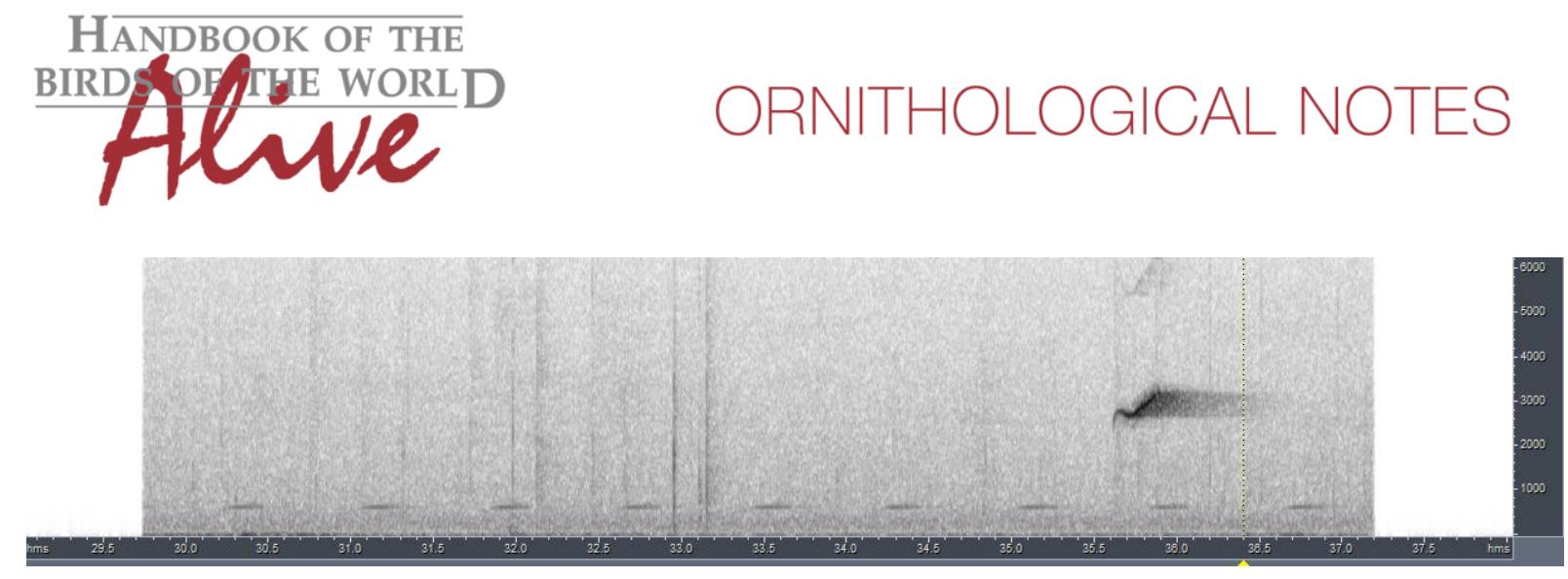

There is only one available recording of nominate race frater:

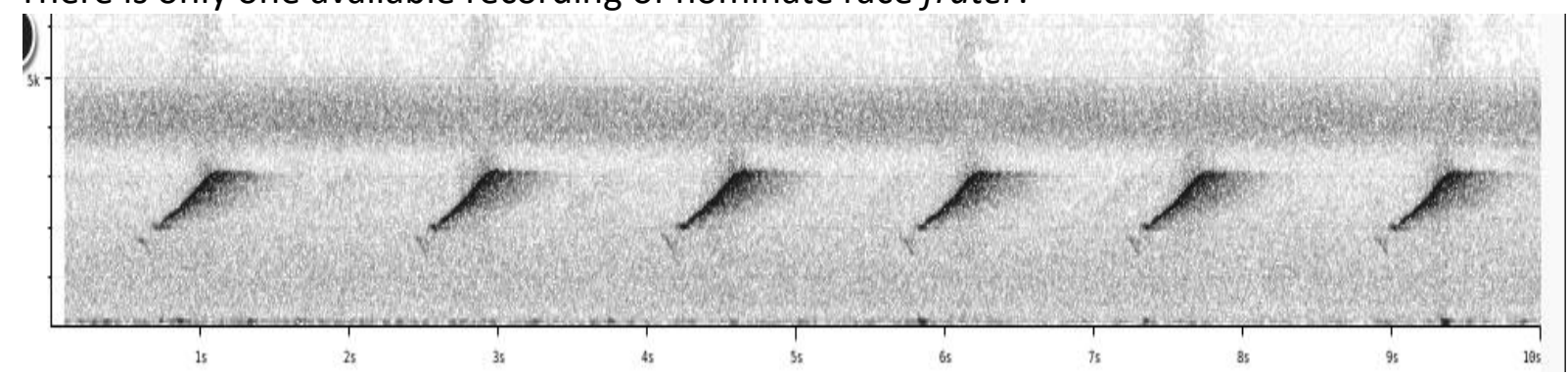

Pratt \& Beehler (2015) mention a.o. an upslurred whistle 'wuree' (which is a good transcription for the frater recording), without assigning it to a specific race.

There seems to be too little evidence to conclude that race frater has a truly distinctive voice.

Vocalisations of canescens (NE Australia) don't seem to differ substantially from New Guinea birds. But obviously the same can be said when comparing with Black-faced Monarch $M$. melanopsis, as illustrated by the following example from New South Wales:

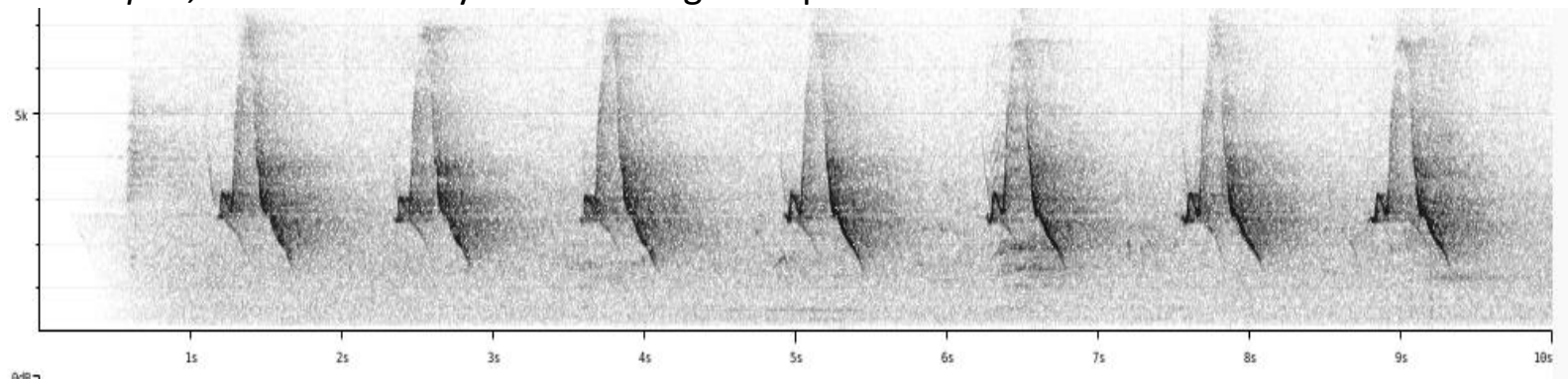

At most, one could observe that the up and down whistles of canescens seem to have a little 'hook' at the start, which is shared with Black-faced Monarch and apparently not with periophthalmicus $(n=2)$, but more recordings needed to confirm whether this is truly a distinctive feature.

In any case, based on presently available recordings, vocal differences seem to be small at most.

This note was finalized on 22nd January 2016, using sound recordings available on-line at that moment. We would like to thank in particular the sound recordists who placed their recordings for this species on XC and ML: Alexandra Class, Benjamin Freeman, Frank Lambert, John V Moore and Thane Pratt. 


\section{References}

Pratt, T.K., Beehler, B.M. (2015). Birds of New Guinea. Second Edition. Princeton University Press. Princenton and Oxford.

Tobias, J.A., Seddon, N., Spottiswoode, C.N., Pilgrim, J.D., Fishpool, L.D.C. \& Collar, N.J. (2010). Quantitative criteria for species delimitation. Ibis 152(4): 724-746.

\section{Recommended citation}

Boesman, P. (2016). Notes on the vocalizations of Black-winged Monarch (Monarcha frater). HBW Alive Ornithological Note 193. In: Handbook of the Birds of the World Alive. Lynx Edicions, Barcelona. (retrieved from http://www.hbw.com/node/932138 on 29 August 2016). 